(2) OPEN ACCESS

\title{
New tobacco products, old advertising strategies: point-of-sale advertising in Guatemala
}

\author{
Joaquin Barnoya 주 , ${ }^{1,2}$ Diego Monzon, ${ }^{1}$ Jose Pinetta, ${ }^{1}$ Graziele Grilo 주 , \\ Joanna E Cohen
}

\begin{abstract}
- Additional material is published online only. To view please visit the journal online (http://dx.doi.org/10.1136/ tobaccocontrol-2020-055681).

'Departamento de Investigacion, Unidad de Cirugia Cardiovascular, Guatemala, Guatemala

${ }^{2}$ Research Department, Integra Cancer Institute, Guatemala, Guatemala

${ }^{3}$ Institute for Global Tobacco Control, Johns Hopkins Bloomberg School of Public Health, Baltimore, Maryland, USA
\end{abstract}

\section{Correspondence to}

Dr Joaquin Barnoya, Departamento de Investigacion, Unidad de Cirugia Cardiovascular, Guatemala 01010, Guatemala; jbarnoya@post.harvard.edu

Received 3 February 2020 Revised 13 June 2020 Accepted 16 June 2020 Published Online First 19 August 2020

\section{ABSTRACT \\ Objective Capsule cigarettes, electronic cigarettes} (e-cigarettes) and heated tobacco products (HTPs) are now readily available in Guatemala. As in most countries, the point-of-sale (POS) remains an important marketing channel for the tobacco industry. Therefore, we sought to characterise the POS marketing of these products in the two largest cities in Guatemala.

Methods Convenience stores were randomly surveyed in mid and high socioeconomic status (SES) neighbourhoods in Guatemala City $(n=60)$ and Quetzaltenango $(n=15)$ in 2019. We adapted a previously implemented checklist to assess the availability of interior advertising of capsule cigarettes, ecigarettes and HTP. Data entry was done in Kobo toolbox and analysis in STATA.

Results All stores sold conventional and flavoured capsule cigarettes, 78\% e-cigarettes and 68\% HTP. Most cigarette advertising was for capsule cigarettes. E-cigarettes were more likely to be sold in Guatemala City (96\%) than in Quetzaltenango (13\%). HTPs were only found in Guatemala City (85\%), with no difference between high and medium SES neighbourhoods. Median number of ads for cigarettes and capsule cigarettes was higher in the high SES neighbourhood. Most e-cigarettes $(83 \%)$ and HTP $(74 \%)$ were found $<50 \mathrm{~cm}$ from candy. $\mathrm{E}$-cigarettes and HTP were available in a wide range of flavours. All stores that sold HTP had flavoured HEETS (amber, bronze, turquoise, yellow, blue and purple). Conclusion We found a high prevalence of advertising for capsule cigarettes, e-cigarettes and HTP at the POS. The POS, a crucial advertising channel for the tobacco industry, is now being used for new products and therefore needs to be urgently regulated.

\section{INTRODUCTION}

The point-of-sale (POS) environment is an important channel used by the tobacco industry to communicate with current, former and potential smokers. ${ }^{1}$ Exposure to POS retail advertising may influence smoking initiation among youth and young adults and relapse among former smokers. ${ }^{1}$ Therefore, the POS has become one of the main advertising channels for the industry, particularly in countries where other forms of advertising (eg, billboard and newspaper) have been banned to comply with the Framework Convention on Tobacco Control (FCTC). ${ }^{2} \mathrm{~A}$ POS advertising ban can correct young people's overestimations of peer smoking prevalence, change perceptions about smoking and decrease the rates of impulsive tobacco purchasing. ${ }^{134}$ Despite smokers' support for POS advertising bans, most countries lack comprehensive legislation that includes the POS. ${ }^{5} 6$

Guatemala signed and ratified the FCTC in 2004 but only smoke-free environments have been implemented. Regarding advertising, only billboards within $500 \mathrm{~m}$ from schools, universities and sports facilities are banned. ${ }^{7}$ We have previously documented the retail POS environment in Guatemala in 2008 and found a large amount of tobacco advertising, particularly in convenience stores within gas stations compared with supermarkets, pharmacies and kiosks. ${ }^{8}$ Given that an estimated $84 \%$ of adolescent smokers purchase cigarettes at a convenience store it is likely that exposure to POS advertising is high. ${ }^{9}$

Capsule cigarettes, electronic cigarettes (e-cigarettes) and heated tobacco products (HTP) are all legally available in Guatemala. Capsule cigarettes have a capsule in the filter that consumers crush to release a flavour. HTPs were first introduced in 2017. IQOS-Philip Morris International's (PMI) HTP-uses HEETS (known as HeatSticks) that contain tobacco and are disposable cartridges. Guatemala is the third largest consumer of capsule cigarettes (19\% of the market share) in Latin America and an estimated 5.7\% of adolescents use electronic (e-cigarettes). ${ }^{9}$ There are no data on HTP use by adults or adolescents.

As e-cigarettes and HTP spread worldwide, it is important to understand what marketing strategies the industry is using to reach consumers. Therefore, we sought to provide a detailed description of e-cigarettes and HTP POS advertising in convenience stores within gas stations in the two largest cities in Guatemala. These data can inform local policy-makers and tobacco control advocates on how new, alternative tobacco products are being advertised at the POS in a country with weak FCTC implementation.

\section{METHODS}

In 2019, we visited a random sample of convenience stores within gas stations in high and middlesocioeconomic status (SES) neighbourhoods in Guatemala City (population 5103 685). SES was defined by the average unit price (US\$1743 and US\$1071, respectively) of land. ${ }^{10}$ Low SES neighbourhoods were excluded due to safety reasons. To select stores, we first mapped each one with GPS location. All stores were assigned a number using a random digit generator to select those to be audited. In addition, we surveyed all convenience stores within gas stations in Quetzaltenango (population 750 000). This city is located about 3 hours 
Table 1 Availability and POS advertising of cigarettes, capsule cigarettes, e-cigarettes and HTP in Guatemala 2019

\begin{tabular}{|c|c|c|c|c|}
\hline \multirow[b]{2}{*}{ No of stores (\%) } & \multicolumn{2}{|c|}{$\begin{array}{l}\text { Guatemala city } \\
\text { Neighbourhood SES }\end{array}$} & \multirow[b]{2}{*}{$\begin{array}{l}\text { Quetzaltenango } \\
(\mathrm{n}, \%)\end{array}$} & \multirow[b]{2}{*}{$P$ value } \\
\hline & $\begin{array}{l}\text { High } \\
(\mathrm{n}, \%)\end{array}$ & $\begin{array}{l}\text { Middle } \\
(\mathrm{n}, \%)\end{array}$ & & \\
\hline \multicolumn{5}{|l|}{ Availability } \\
\hline Cigarettes & $30(100)$ & $30(100)$ & $15(100)$ & 0.9 \\
\hline Capsule cigarette & $30(100)$ & $30(100)$ & $15(100)$ & 0.9 \\
\hline e-cigarettes & 29 (96.6) & $28(93.3)$ & $2(13.3)$ & $<0.001$ \\
\hline HTP & $26(86.6)$ & $25(83.3)$ & $0(0)$ & $<0.001$ \\
\hline \multicolumn{5}{|l|}{ Stores with interior ads } \\
\hline Cigarettes & $26(87)$ & $29(97)$ & $7(47)$ & $<0.001$ \\
\hline Capsule cigarette & $24(80)$ & $26(87)$ & $6(40)$ & $<0.001$ \\
\hline e-cigarettes & $13(43)$ & $20(67)$ & $0(0)$ & $<0.001$ \\
\hline HTP & $0(0)$ & $1(3)$ & $0(0)$ & 0.9 \\
\hline $\begin{array}{l}\text { Stores }(\%) \text { with cigarettes } \\
\text { next to the cash register }\end{array}$ & $0(0)$ & $0(0)$ & $5(33)$ & $<0.001$ \\
\hline $\begin{array}{l}\text { Stores }(\%) \text { with e- } \\
\text { cigarettes next to the cash } \\
\text { register }\end{array}$ & $25(86.2)$ & $20(71.4)$ & $2(100)$ & 0.5 \\
\hline $\begin{array}{l}\text { Stores (\%) with HTP next } \\
\text { to the cash register }\end{array}$ & $13(50)$ & $10(40)$ & $\mathrm{N} / \mathrm{A}$ & 0.5 \\
\hline $\begin{array}{l}\text { Stores (\%) with cigarettes } \\
<50 \mathrm{~cm} \text { of candy }\end{array}$ & 29 (96.6) & $28(93.3)$ & $8(53.3)$ & $<0.001$ \\
\hline $\begin{array}{l}\text { Stores }(\%) \text { with e- } \\
\text { cigarettes }<50 \mathrm{~cm} \text { of } \\
\text { candy }\end{array}$ & $28(96.5)$ & $24(85.7)$ & $2(100)$ & $<0.001$ \\
\hline $\begin{array}{l}\text { Stores (\%) with HTP } \\
<50 \mathrm{~cm} \text { of candy }\end{array}$ & $24(82.7)$ & $24(85.7)$ & $0(0)$ & $<0.01$ \\
\hline
\end{tabular}

$(206 \mathrm{~km})$ northwest of Guatemala City and is the second largest in the country.

To assess the prevalence and characteristics of POS advertising and other marketing techniques, a previously implemented checklist was adapted to include capsule cigarettes, e-cigarettes and HTP. ${ }^{11}$ The checklist (online supplementary appendix 1) included advertising type, feature, brand and product placement (eg, behind the counter, next to the cash register, near candy). The store was used as the unit of analysis. Comparisons were made across products and between cities using medians (25th75 th percentiles) and percentages. Data were entered using the app Kobo Toolbox and $\mathrm{X}^{2}$ (Fisher's exact test when appropriate) and Kruskal-Wallis tests done in STATA 13.0.

\section{RESULTS}

In total, 60 stores in Guatemala City and 15 in Quetzaltenango were approached and all were surveyed. Most stores (75\%) had one cash register. The availability of e-cigarettes was significantly higher in Guatemala City (96\%) than in Quetzaltenango $(13 \%)$ (table 1). HTPs were only found in Guatemala City $(85 \%)(\mathrm{p}<0.01)$. All stores had interior ads; most were for capsule cigarettes $(87.5 \%)$. The prevalence of interior tobacco advertising was high (85\%) and most was found in Guatemala City (89\%) (table 1). Total median numbers of interior ads were higher in high SES $(7.5,4-11)$ compared with middle SES (3, $2-4)$ neighbourhoods and Quetzaltenango $(0,0-4) \quad(p<0.01)$. The median number of interior cigarette ads was significantly $(<0.01)$ higher in the high $(4.5,2-6)$ compared with the middle $(1,1-2)$ SES neighbourhoods and Quetzaltenango $(2,1-4)$. The most commonly advertised cigarette brand was Pall Mall (British
American Tobacco) capsule cigarettes. Most e-cigarettes (83\%) and HTP $(74 \%)$ were found $<50 \mathrm{~cm}$ from candy.

All stores that sold e-cigarettes and HTP had flavoured products available. The most frequent e-cigarette flavours advertised were fresh apple, dark cherry and tobacco blend. Flavoured HTPs are sold as a separate unit called HEETS. Each flavour is identified by a different colour. We found HEETS in the following colours: amber (light wood and nut smell), bronze (cacao and dry fruit), turquoise (menthol, lightly spiced), yellow (citrus), blue (menthol and vanilla) and purple (menthol and fruit).

\section{DISCUSSION}

To the best of our knowledge, this is the first study documenting POS advertising of e-cigarettes and HTP in an upper-middleincome country. According to our findings, POS advertising now includes e-cigarettes and HTP. Regarding cigarettes, most of the advertising is for capsule cigarettes.

In Guatemala, compared with 2008, e-cigarettes and HTPs are now readily available and strategically placed to reach children. In most stores, both products were found near candy. Regarding cigarettes, there was an increase in the prevalence of interior ads that can be seen from the outside and an increase in interior tobacco advertising, especially in high SES neighbourhoods. ${ }^{8}$ There was also a substantially higher prevalence of ads/products $<50 \mathrm{~cm}$ from candy in high and mid-SES stores in 2019 vs 2008 (97\% vs $87 \%$ and $93 \%$ vs $28 \%$, respectively). In addition, capsule cigarette advertising is now widespread at the POS. This might be one of the reasons why Guatemala is one of the highest consumers of capsule cigarettes in Latin America. ${ }^{12}$

e-cigarettes are readily available, unregulated and advertised at the POS in Guatemala (particularly in high SES neighbourhoods). Advertising has been found to target specific socioeconomic consumers and where there is weak tobacco control. In the USA, for example, it has been found that higher SES neighbourhoods have more e-cigarette advertising. ${ }^{13}$ In addition, POS advertising is higher in areas with weak tobacco taxes and smoke-free policies (like Guatemala). ${ }^{13}$

HTPs were first introduced in Asia where consumption is rapidly increasing. ${ }^{14}$ Our findings are consistent with the limited evidence available on HTP POS advertising. In Israel, HTPs were also located close to candy. ${ }^{15}$ As opposed to conventional cigarettes, in Guatemala, at the time of data collection PMI was only using product placement to advertise IQOS and HEETS. Countries where HTPs are already available should monitor advertising and consider banning HTP display at the POS as they do with any other tobacco product.

In Quetzaltenango, the number of stores selling e-cigarettes and the prevalence of tobacco advertising were lower than in Guatemala City (HTPs were not found at all). Even though the reasons why HTPs are only sold in Guatemala City are unclear, local health officials should remain vigilant to the emergence of these products in other areas where they are not yet available.

Flavoured e-cigarettes and HTPs are now readily available in the market. As opposed to e-cigarettes that are using fruit names for each flavour, PMI is using colours to differentiate them. This should be taken into account by tobacco control advocates to ensure that colours are also included in advertising bans.

Our study has strengths and limitations. As the same methodology (ie, store sampling, data collection, entry form) was used from our previous study we can be certain that new products are available at the POS, in the two most populated cities of the country. In addition, this is the first study documenting all three products (capsule cigarettes, e-cigarettes and HTP) in a country 
with weak FCTC implementation. However, our randomly selected sample is only from convenience stores within gas stations and in middle and high SES neighbourhoods and cities. Consequently, the findings cannot be generalised nationwide or to other stores (eg, supermarkets, corner stores). However, since e-cigarettes are expensive it is unlikely they would be available in corner stores in low SES neighbourhoods. ${ }^{16}$ In addition, as the market rapidly evolves, other products could have been introduced since we surveyed stores. Therefore, as products become more accessible and affordable, we recommend continuously monitoring the POS using a more widely used data collection instrument to allow for international comparisons. ${ }^{17}$

In conclusion, the POS continues to be a major advertising venue to the tobacco and now e-cigarette industries in Guatemala. Our findings highlight the need to include the POS in any comprehensive advertising ban, which should also include e-cigarettes and HTP as the market rapidly evolves.

\section{What this paper adds}

- Electronic cigarettes (e-cigarettes) and heated tobacco products (HTPs) are becoming increasingly popular, particularly in countries with weak Framework Convention on Tobacco Control implementation, like Guatemala.

- Evidence documenting e-cigarettes and HTP advertising is limited and needed in order to inform policies to restrict advertising of these emerging products.

- The point of sale (POS) remains a leading marketing channel for the tobacco industry to communicate with future, current and former users.

- According to our findings, e-cigarettes and HTPs are being advertised at the POS and are strategically placed to attract children and adolescents in Guatemala.

Contributors JB, DM, JP and GG worked on study design and adapted the data collection instrument. DM and JP worked on data collection and entry. JB, DM, JP, GG and JEC worked on data analysis, manuscript writing and approved the final manuscript.

Funding This study was funded by Bloomberg Philanthropies' Bloomberg Initiative to Reduce Tobacco Use.

Competing interests None declared.

Patient consent for publication Not required.

Provenance and peer review Not commissioned; externally peer reviewed.
Open access This is an open access article distributed in accordance with the Creative Commons Attribution Non Commercial (CC BY-NC 4.0) license, which permits others to distribute, remix, adapt, build upon this work non-commercially, and license their derivative works on different terms, provided the original work is properly cited, appropriate credit is given, any changes made indicated, and the use is non-commercial. See: http://creativecommons.org/licenses/by-nc/4.0/.

\section{ORCID iDs}

Joaquin Barnoya http://orcid.org/0000-0002-1731-479X

Graziele Grilo http://orcid.org/0000-0002-8377-4794

Joanna E Cohen http://orcid.org/0000-0002-3869-3637

\section{REFERENCES}

1 Robertson L, Cameron C, McGee R, et al. Point-of-sale tobacco promotion and youth smoking: a meta-analysis. Tob Control 2016;25:e83-9.

2 Lavack AM, Toth G. Tobacco point-of-purchase promotion: examining tobacco industry documents. Tob Control 2006:15:377-84.

3 McNeill A, Lewis S, Quinn C, et al. Evaluation of the removal of point-of-sale tobacco displays in Ireland. Tob Control 2011;20:137-43.

4 Edwards R, Ajmal A, Healey B, et al. Impact of removing point-of-sale tobacco displays: data from a new Zealand youth survey. Tob Control 2017;26:392-8.

5 van Mourik D-JA, Candel MJJM, Nagelhout GE, et al. Support for a point-of-sale cigarette display ban among smokers: findings from the International tobacco control (ITC) Netherlands survey. BMC Public Health 2018;18:740.

6 Li L, Borland R, Yong H-H, et al. Impact of Point-of-Sale tobacco display bans in Thailand: findings from the International tobacco control (ITC) Southeast Asia survey. Int J Environ Res Public Health 2015;12:9508-22.

7 Diario de Centro América. Decreto 50-2000 Guatemala: Gobierno de Guatemala, 2000 [updated Miércoles 6 de Septiembre. Tomo CCLXIV. Available: https://www. congreso.gob.gt/detalle_pdf/decretos/638 [Accessed 3 Apr 2020].

8 Barnoya J, Mejia R, Szeinman D, et al. Tobacco point-of-sale advertising in Guatemala City, Guatemala and Buenos Aires, Argentina. Tob Control 2010;19:338-41.

9 Global Youth Tobacco Survey. Guatemala 2015. in: World Health organization. Washington, DC: Pan American Health Organization, 2015.

10 Soy 502 . Donde están Los metros cuadrados más caros Y baratos de la ciudad? Guatemala: soy 502, 2017. Available: https://www.soy502.com/articulo/donde-estanmetros-cuadrados-mas-caros-baratos-ciudad-68696 [Accessed April 2 2020].

11 Cohen JE, Planinac LC, Griffin K, et al. Tobacco promotions at point-of-sale: the last hurrah. Can J Public Health 2008;99:166-71.

12 Moodie C, Thrasher JF, Cho YJ, et al. Flavour capsule cigarettes continue to experience strong global growth. Tob Control 2019;28:595-6.

13 Rose SW, Barker DC, D'Angelo $\mathrm{H}$, et al. The availability of electronic cigarettes in U.S. retail outlets, 2012: results of two national studies. Tob Control 2014;23 Suppl 3:iii10-16.

14 Stoklosa M, Cahn Z, Liber A, et al. Effect of IQOS introduction on cigarette sales: evidence of decline and replacement. Tob Control 2020;29:381-7.

15 Bar-Zeev Y, Levine H, Rubinstein G, et al. IQOS point-of-sale marketing strategies in Israel: a pilot study. Isr J Health Policy Res 2019;8:11.

16 Chacon V, Arriaza A, Cavazos-Rehg P, et al. Availability, price, and packaging of electronic cigarettes and E-Liquids in Guatemala City Retailers. Nicotine Tob Res 2018:20:253-7.

17 Henriksen L, Ribisl KM, Rogers T, et al. Standardized tobacco assessment for retail settings (stars): dissemination and implementation research. Tob Control 2016;25:i67-74. 